\title{
The first two laparoscopic pancreaticoduodenectomy cases in the eastern Black Sea region
}

\author{
Servet Karagül,' Oktay Karaköse² \\ 'Department of Gastroenterological Surgery, University of Health Sciences, Samsun Training and Research Hospital, Samsun, Turkey \\ 2Department of Oncological Surgery, University of Health Sciences, Samsun Training and Research Hospital, Samsun, Turkey
}

\begin{abstract}
Laparoscopic pancreaticoduodenectomy has similar oncological outcomes to open pancreaticoduodenectomy. As minimally invasive surgery, a laparoscopic procedure is more advantageous in terms of blood loss, the length of hospital stay, and the occurrence of wound site complications. Presently described are 2 cases: an 84-year-old man with a tumor in the ampulla of Vater and a 74-year-old woman with distal bile duct cancer. Both were successfully treated with a laparoscopic Whipple procedure. In centers that perform a high volume of pancreatic surgery and advanced laparoscopic procedures, this surgery can be performed successfully using the appropriate techniques.
\end{abstract}

Keywords: Bile duct tumor; laparoscopic surgery; pancreatic cancer; Whipple.

\section{Introduction}

Gagner and Pomp described the first laparoscopic pancreaticoduodenectomy (LPD) in 1994. ${ }^{[1]}$ Despite the advantages of minimal invasive surgery, such as early mobilization, reduced wound site complications, and early bowel movements, laparoscopic surgery has not been accepted as a standard procedure in pancreaticoduodenectomy. LPD has similar oncologic outcomes and postoperative complications when compared with open pancreaticoduodenectomy (OPD). ${ }^{[2]}$ However, the need for advanced surgical skills and the complexity of operation have resulted in slow adoption of the laparoscopic procedure. The two patients presented herein were treated in Samsun Training and Research Hospital and the first cases treated by LPD in the eastern Black Sea region of Turkey.

\section{Case Report}

\section{Case 1}

An 84-year-old man was referred to our clinic for further examination of obstructive jaundice. His medical history was unremarkable. Physical examination revealed mild tenderness in the right upper quadrant of the abdomen, but no mass was palpable. Laboratory tests results were as follows: hemoglobin (Hb): $12.9 \mathrm{~g} / \mathrm{dL}$, total bilirubin: 15 $\mathrm{mg} / \mathrm{dL}$, direct bilirubin: $9 \mathrm{mg} / \mathrm{dL}$, aspartate aminotransferase (AST): $120 \mathrm{IU} / \mathrm{L}$, alanine transaminase (ALT): 145 IU/L, cancer antigen 19-9 (CA19-9): 66 U/ml. Computed tomography demonstrated a tumor in the ampulla of Vater. Endoscopic retrograde cholangiopancreatography (ERCP) confirmed the ampullary tumor, and a stent was placed into the bile duct. Two weeks later, total biliru- 
bin was $6 \mathrm{mg} / \mathrm{dL}$, direct bilirubin was $4 \mathrm{mg} / \mathrm{dL}$, and the patient underwent a LPD. Intraoperative blood loss was $150 \mathrm{cc}$ and operating time was 540 minutes. The mass was identified as a well-differentiated adenocarcinoma (T1NOM0) in histopathological examination. None of the lymph nodes were involved. The patient recovered uneventfully and he went to an other hospital for medical oncological consultation. They did not consider chemotherapy and the patient remained disease free for seven months after surgery, acording to CA19-9 level and contrast-enhanced computed tomography. At the end of the seventh month, the patient had a bleeding problem after a prostate procedure and he died on the following day, due to an acute myocardial infarction.

\section{Case 2}

A 74-year-old woman was admitted with complaints of itching and jaundice for 2 months. She had a medical history of diabetes mellitus, hypertension, and coronary artery disease. Jaundice of the sclera and skin was observed on physical examination. The patient was morbidly obese, with a body mass index (BMI) of $48.8 \mathrm{~kg} / \mathrm{m}^{2}$. Laboratory tests revealed $\mathrm{Hb}: 12.1 \mathrm{~g} / \mathrm{dL}$, total bilirubin: $22 \mathrm{mg} / \mathrm{dL}$, direct bilirubin: $17 \mathrm{mg} / \mathrm{dL}$, AST: $205 \mathrm{IU} / \mathrm{L}$, ALT: 166 IU/L, CA19-9: 37.5 U/mL. Ultrasonography showed dilated intrahepatic and extrahepatic bile ducts. Computed tomography and magnetic resonance imaging revealed a mass in the distal common bile duct, and an obstructive mass was observed on ERCP. We performed percutaneous transhepatic cholangiography and placed an external biliary drainage catheter. Three weeks later, total bilirubin was $10 \mathrm{mg} / \mathrm{dL}$, direct bilirubin was $6 \mathrm{mg} / \mathrm{dL}$ and the patient underwent LPD. Intraoperative blood loss was $400 \mathrm{cc}$ and surgery time was 495 minutes. Follow-up was unevetful for the first two postoperative days, but on the third day she developed tachycardia which was medically refractory. The patient died from cardiac complications on postoperative day four. As with the first patient, histopathological examination identified a well-differentiated adenocarcinoma and there was no lymph nodes involvement.

\section{Surgical Technique}

Both patients were immobilized in Lloyd-Davies position with $30^{\circ}$ reverse Trandelenburg. A nasogastric tube and urinary catheter were inserted. After insuffliation of the abdomen, a $12 \mathrm{~mm}$ trocar was inserted approximately 2 $\mathrm{cm}$ inferior to umblicus. Two $12 \mathrm{~mm}$ trocars were placed to right and left lower quadrant, lateral of the rectus muscles. A five mm trocar was inserted from left upper quadrant. Additionally, a Nathanson retractor was used to elevate the liver and a 5-mm trocar was placed during the hepatobiliary dissection through the right upper quadrant. Abdominal pressure was maintained at $13 \mathrm{mmHg}$ with carbon dioxide $\left(\mathrm{CO}_{2}\right)$ insufflation.

The gastrocolic ligament was divided to enter the lesser sac. Kocher maneuver was performed. The left renal vein and vena cava inferior were visualized and the third part of the duodenum was completely freed from the mesocolon. The jejunum was transected approximately $10 \mathrm{~cm}$ distally to Treitz's ligament using a laparoscopic stapler. The gastrohepatic ligament was divided, the hepatic artery was skeletonized and the hepatoduodenal lymph nodes were dissected. The right gastric artery and gastroduodenal artery were identified and transected (Fig. 1). The common bile duct was isolated. Distal gastrectomy was performed using $60 \mathrm{~mm}$ laparoscopic staplers. The pancreas was mobilized from the anterior surface of the superior mesenteric vein and the portal vein with blunt dissection (Fig. 2). The pancreas was transected using harmonic shears. After cholecystectomy, the common bile duct was divided proximal to the cystic duct. The head of the pancreas and uncinate process were dissected from the portal vein and superior mesenteric artery.

The proximal jejunal stump was passed retrocolically into the upper abdomen. Following placement of a 5-French catheter into the Wirsung duct, one-layer extramucosal pancreaticojejunostomy (PJ) was performed with 3-0 polypropylene running suture, as described previously ${ }^{[3]}$ (Fig. 3). Hepaticojejunostomy (HJ) was performed by the same technique with a 4-0 polydioxanone, $10-15 \mathrm{~cm}$ distal to the PJ (Fig. 4). The jejunum was transected $50 \mathrm{~cm}$ distal to the $\mathrm{HJ}$ and gastroenterostomy was done with a 60 $\mathrm{mm}$ stapler. Finally, the biliary limb was anastomosed to

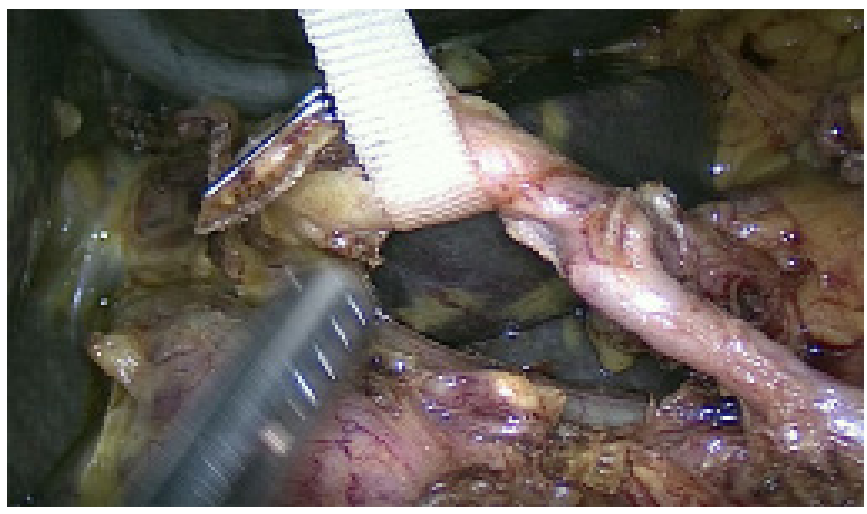

Figure 1. Dissection of the hepatoduodenal ligament. 


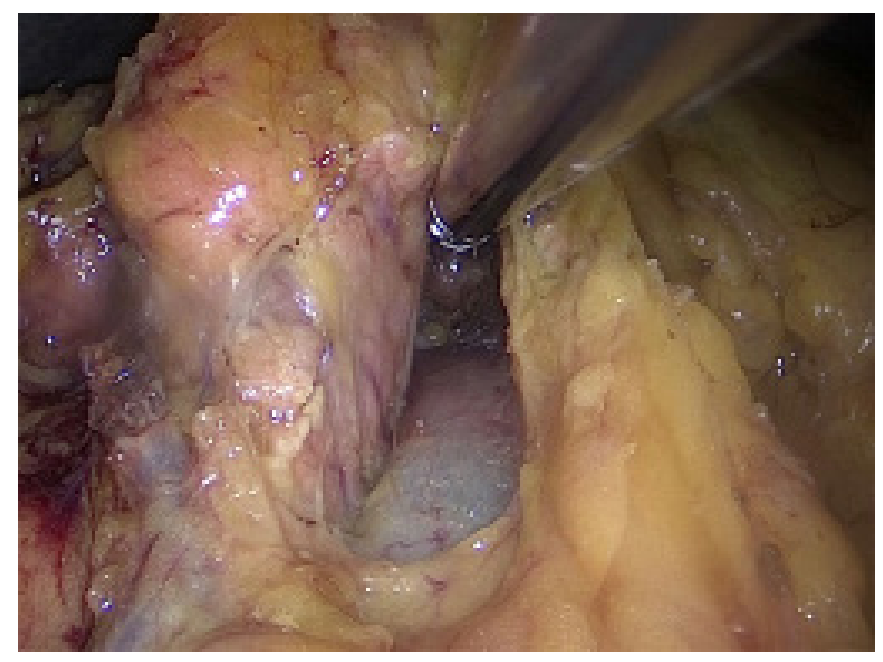

Figure 2. Mobilization of the pancreatic neck.

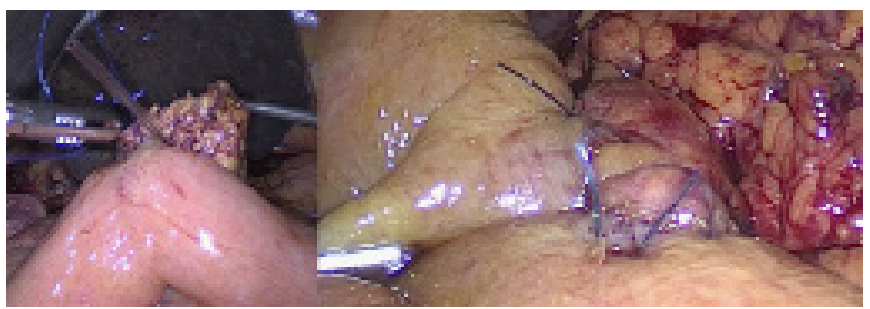

Figure 3. Anastomosis of pancreaticojejunostomy.

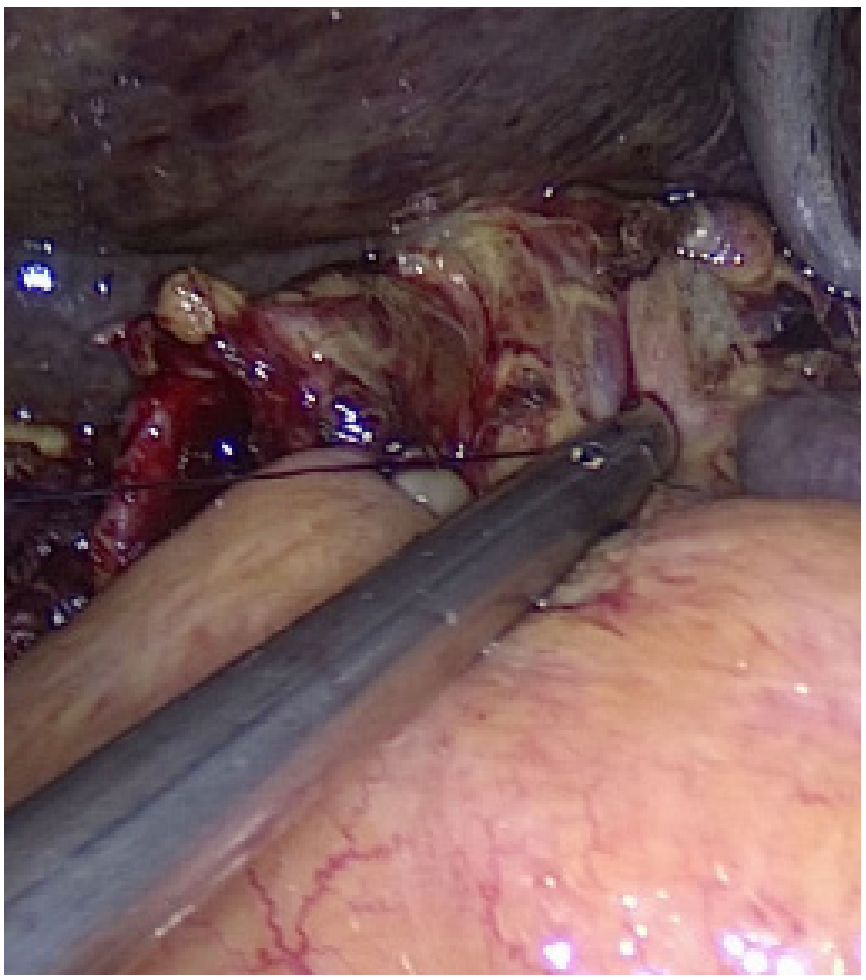

Figure 4. Anastomosis of hepaticojejunostomy.

the alimentary limb as Roux-en-Y enteroenterostomy. The subxiphoidal trocar site was enlarged and the specimen was extracted. Two drains were placed behind the $\mathrm{HJ}$ and PJ anastomoses.

\section{Discussion}

Although no differences have been reported in the oncologic outcomes of OPD and LPD, the latter is more advantageous in terms of blood loss and length of hospital stay. ${ }^{[3]}$ However, in terms of surgery time, LPD is a longer procedure than OPD. Despite its advantages, it will take time for the laparoscopic approach to gain favor due to the complexity of the surgery. Technological advances may accelerate this process. We successfully performed laparoscopic Whipple procedure in our clinic after gaining extensive experience with OPD and advanced laparoscopic surgery. The procedures were completed uneventfully in both cases.

Because these were our first cases, we were very careful with patient selection. In both cases, the mass was located within the head of the pancreas with no suspicion of vascular invasion. Pathology results obtained later were consistent with early-stage cancer. However, the patients exhibited obstructive jaundice, and we performed biliary drainage before surgery in both cases. This issue is debated in the literature, with the view emerging in recent years that biliary drainage is not an absolute necessity. There is also a lack of consensus on the impact of preoperative biliary drainage on postpancreatectomy hemorrhage. ${ }^{[4,5]}$

Pancreatic fistula is the most challenging morbidity in the pancreaticoduodenectomy procedure. Therefore, appropriate anastomosis technique is one of issues of greatest concern. However, previous studies have shown no difference between anastomosis techniques in terms of preventing pancreatic fistula. ${ }^{[6,7]}$ We preferred the extramucosal technique for $\mathrm{PJ}$ anastomosis that we used in our previous cases. ${ }^{[3]}$ We have also used this technique in a substantial proportion of our patients undergoing OPD because it is easily implemented and reduces surgery time. We were able to apply the technique safely in our LPD cases and easily handle the most difficult aspect of the procedure.

Elderly patients have longer hospital stays and significantly higher incidence of cardiac problems following pancreaticoduodenectomy ${ }^{[8]}$ Our two patients were also advanced in age. Our first patient was 84 years old and in good physical condition. In early postoperative period active hemorrhage was noted in the drain, two hours after surgery. We explored through the specimen extraction site with the patient under general anesthesia. The hem- 
orrhage was found to originate from a small branch of the superior mesenteric artery and was controlled with ligation. In this case, we used bipolar ligation device when dissecting the uncinate process and had not done any other ligation. We now believe that the use of clips would be beneficial, at least for vascular structures. The patient experienced no complications during follow-up. Oral feeding was resumed on postoperative day 4 and he was discharged uneventfully.

Our second patient had an obstructing mass in the distal common bile duct and long-term complaints of jaundice and itching. She was morbidly obese and suffered from diabetes mellitus and cardiac problems. There were no problems for the first two days after surgery. However, the patient developed medically refractory tachycardia postoperatively and died due to cardiac problems. We had initial reservations about performing surgery in this patient. We were confronted with a morbidly obese patient with several comorbidities and a seemingly early-stage mass in the ampulla of Vater. Ultimately, we felt the patient would benefit from surgery.

We do not consider patient age a contraindication to pancreatectomy. Of course, the presence of concomitant diseases will increase morbidity. The short- and relatively long-term results of the Whipple procedure are similar in elderly patients and young patients. ${ }^{[9]}$ On the other hand, the populations of developing countries like Turkey are aging. A large majority of pancreatic cancer patients are also elderly. Therefore, the coming years will bring increases in both the number and age of patients undergoing surgery for pancreatic cancer.

Few centers in the eastern Black Sea region perform pancreaticoduodenectomy. One of these centers is our clinic. However, there were no previous examples of cases treated laparoscopically. The patients we present in this report are the first cases of LPD in this region. In centers that perform a high volume of pancreatic surgeries and with surgeons experienced in advanced laparoscopic surgery, LPD can be performed successfully using the appropriate techniques.

\section{Conclusion}

LPD is a technically feasible procedure for surgeons expe- rienced in OPD and advanced laparoscopic surgery, but patient selection is important, especially in elderly patients with myocardial diseases.

\section{Disclosures}

Informed Consent: Written informed consent was obtained from the patient for the publication of the case report and the accompanying images.

Peer-review: Externally peer-reviewed.

Conflict of Interest: None declared.

\section{References}

1. Gagner M, Pomp A. Laparoscopic pylorus-preserving pancreatoduodenectomy. Surg Endosc 1994;8:408-10. [CrossRef]

2. Boggi U, Amorese G, Vistoli F, Caniglia F, De Lio N, Perrone V, et al. Laparoscopic pancreaticoduodenectomy: a systematic literature review. Surg Endosc 2015;29:9-23. [CrossRef]

3. Karagul S, Kayaalp C, Sumer F, Yagci MA. Extramucosal pancreaticojejunostomy at laparoscopic pancreaticoduodenectomy. J Minim Access Surg 2018;14:76-8. [CrossRef]

4. Asbun HJ, Stauffer JA. Laparoscopic vs open pancreaticoduodenectomy: overall outcomes and severity of complications using the Accordion Severity Grading System. J Am Coll Surg 2012;215:810-9. [CrossRef]

5. Coates JM, Beal SH, Russo JE, Vanderveen KA, Chen SL, Bold RJ, et al. Negligible effect of selective preoperative biliary drainage on perioperative resuscitation, morbidity, and mortality in patients undergoing pancreaticoduodenectomy. Arch Surg 2009;144:841-7. [CrossRef]

6. Liu C, Lu JW, Du ZQ, Liu XM, Lv Y, Zhang XF. Association of Preoperative Biliary Drainage with Postoperative Morbidity after Pancreaticoduodenectomy. Gastroenterol Res Pract 2015;2015:796893. [CrossRef]

7. Singh AN, Pal S, Mangla V, Kilambi R, George J, Dash NR, et al. Pancreaticojejunostomy: Does the technique matter? A randomized trial. J Surg Oncol 2018;117:389-96. [CrossRef]

8. Shrikhande SV, Sivasanker M, Vollmer CM, Friess H, Besselink MG, Fingerhut A; International Study Group of Pancreatic Surgery (ISGPS). Pancreatic anastomosis after pancreatoduodenectomy: A position statement by the International Study Group of Pancreatic Surgery (ISGPS). Surgery. 2017;161:1221-34. [CrossRef]

9. Zhang D, Gao J, Li S, Wang F, Zhu J, Leng X. Outcome after pancreaticoduodenectomy for malignancy in elderly patients. Hepatogastroenterology 2015;62:451-4. 